\title{
Project MICRO in Vermont: An Opportunity for Core Facility Outreach
}

\author{
J. E. Schwarz*, A. M. Taatjes**, and D. J. Taatjes* \\ *Microscopy Imaging Facility, Department of Pathology, University of Vermont, 89 Beaumont Ave., \\ Burlington, VT 05405 \\ ** University of New England, Portland, ME 04005
}

According to the National Academy of Sciences Resources for Involving Scientists in Education (RISE), "The primary function of the science education system is to supply society with scientifically literate citizens" [1]. However, studies have shown that students' attitudes towards and interest in science decline as they progress from elementary school to middle level to high school [2]. Our aim is to reverse this trend, to promote more positive attitudes and to strengthen student interest in science thereby empowering the students to become "scientifically literate citizens".

Since July 1998, Project MICRO (Microscopy In Curriculum - Research Outreach) has put Microscopy Society of America (MSA) members, resources, materials, and microscopes into middle school classrooms all over the country. A collaboration with the Lawrence Hall of Science at UCBerkeley, culminated in the publication of a teacher's manual, Microscopic Explorations in the LHS Great Explorations in Math and Science (GEMS) series. This manual has been the basis for the MSA/MICRO effort to get microscopist-volunteers into classrooms. [3]

In 1999 members of the New England Society for Microscopy (NESM) assembled 3 program "kits" and distributed them to NESM members for use in local schools. A kit was brought back to Vermont to "try out", and 11 years later, we are still using the seeds of that original kit, having exposed over 5,000 children and hundreds of adults to the wonders of the microscopic world. For the last few years, we also have been incorporating some of the activities in Kerry Ruef's The Private Eye, using $5 \mathrm{x}$ eye loupes in interdisciplinary investigations of the local natural environment [5]. The availability of UVM - Microscopy Imaging Center volunteers has encouraged tentative upper elementary school and middle level teachers to utilize microscopes with their students, with our microscopic "festivals" as springboards to further investigations. As microscopes are phased out or replaced in labs at UVM, they are often donated to Project MICRO and then we find "homes" for them in our local schools.

To each school, we bring compound and dissecting microscopes, pocket microscopes, hand lenses, eye loupes, and materials (mostly common items) for 10 Activity Stations. UVM - MIC volunteers facilitate a $2 \frac{1}{2}$ hour program, generally split over 2 sessions where the students investigate properties of magnifying lenses, compare sand samples from many geographic locations, view crystals of various salts, and observe a variety of fabrics to determine how each is made. They compare and contrast shapes, textures, and colors of flowers and leaves, study structures of dried insects, spiders, isopods, and examine a range of imaging and printing techniques. Students compare appearance, specific structures and movement patterns of brine shrimp adults, larvae and eggs, "lift" impressions of their fingerprints to find details of ridge patterns, and scrutinize the minute inhabitants of pond water. At the conclusion of each microscopic festival, the teachers are left with activities for their classes to continue their explorations. The schools that we've "hit" are a mix of urban and rural, some middle schools, others elementary, some schools that have dedicated science 
labs, and others where we've set-up in the library or even the band room. A few summers we've been asked to participate in Science camps and in one town library we are the yearly Summer Science Enrichment program where we tailor the microscope experiences to "mesh" with the theme selected by the Vermont State libraries.

\section{References}

[1] http://www.nas.edu/rise/backg3.htm

[2] K. Skamp and M. Logan, Teaching Science, 51(4), (2005) 8.

[3] http://microscopy.org/education/projectmicro/index.cfm

[4] S. Brady and C. Willard, Microscopic Explorations: A GEMS Festival Teachers's Guide, Lawrence Hall of Science, University of California at Berkeley, Berkeley, CA, 2003.

[5] K. Ruef, The Private Eye- (5X) Looking / Thinking by Analogy, The Private Eye Foundation, Seattle, WA, 1994.

[6] This outreach program is supported by the New England Society for Microscopy, University of Vermont Women's Center, University of Vermont College of Medicine, and Vermont Optechs.
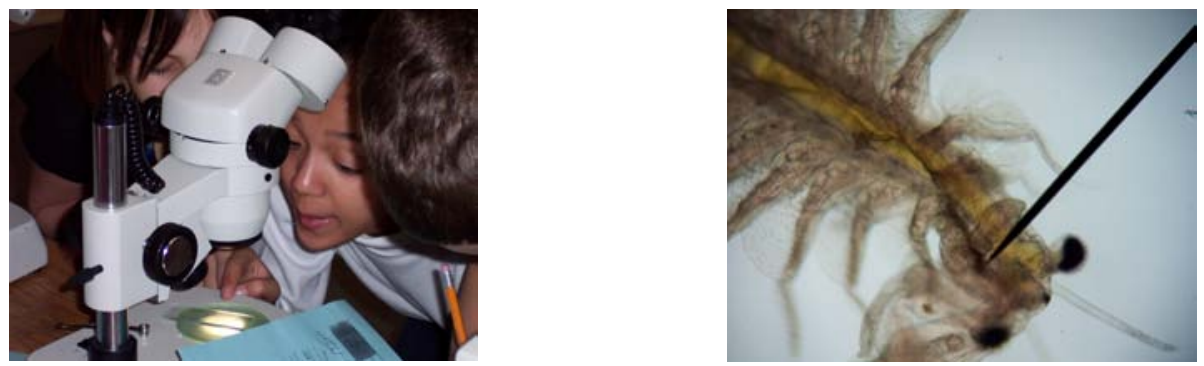

Figure 1. A. $5^{\text {th }}$ grade student preparing to view brine shrimp. B. Adult brine shrimp, $40 \mathrm{x}$
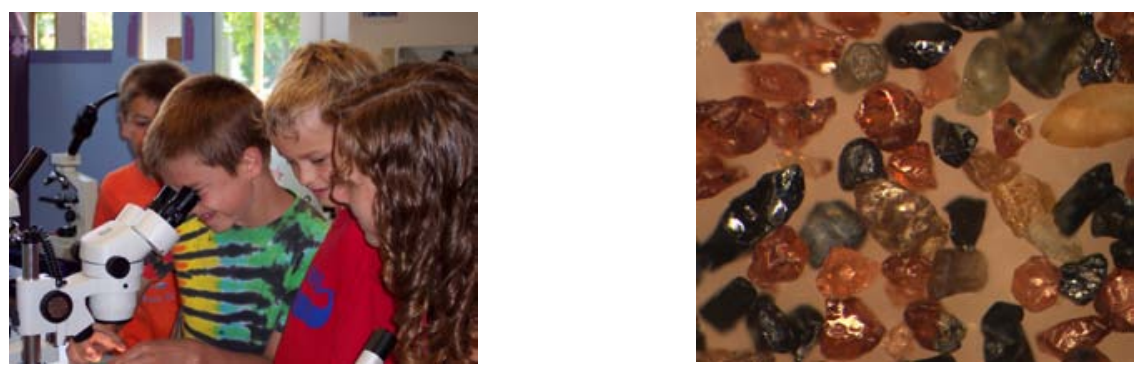

Figure 2. A. Summer Science program.

B. Sand specimen from the Bouquet River, NY, 50x

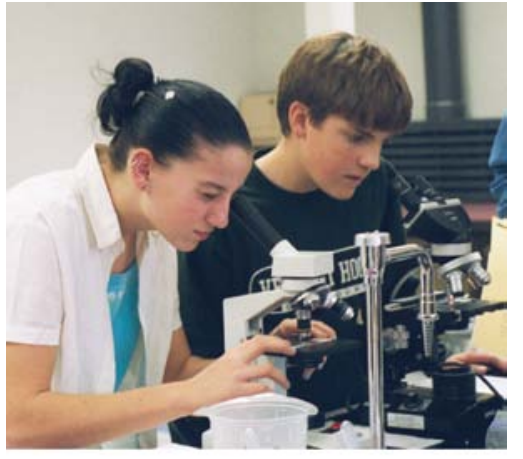

Figure 3. A. Observing pond water specimens.

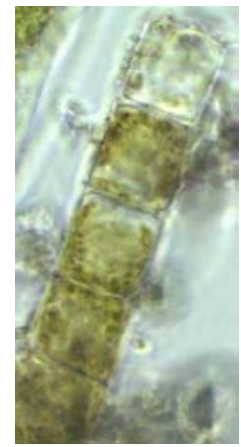

B. Algae, 400x

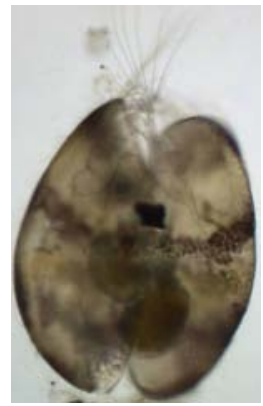

C. Ostracod, 400x 